\title{
Minimal intervention dentistry II: part 2. Management of caries and periodontal risks in general dental practice
}

IN BRIEF

- Outlines risk factors for caries and periodontal diseases.

- Suggests modifying behaviours is the best method for prevention.

- Stresses the importance of a patient profile in recognising the 'at risk' patient.

\author{
C. Lallam ${ }^{1}$ and F. Decup ${ }^{* 2}$
}

The long-term clinical management of caries and periodontal diseases requires a double approach, one that is concerned with both treatment and prevention. Dentists should recognise the risk factors and their likely triggers to be able to implement the right strategy as early as the diagnostic phase. This comprehensive assessment can easily be done in general practice. All it takes is to combine the patient's general information with the systemic and behavioural factors, and the clinical observations with the local factors. The resulting patient profile can thus effectively support treatment by providing the necessary explanations, advice or prescriptions in relation with the clinical procedures. The modifiable risk factors need to be monitored and the behaviours changed to stabilise or limit disease progression. The practitioner's active approach is meant to meet the patient's demand for preventive counselling.

\section{INTRODUCTION}

In clinical activity, treatment and preventive measures should be planned together.

\begin{tabular}{l} 
MINIMAL INTERVENTION \\
DENTISTRY II \\
\hline 1. Contribution of the operating microscope to \\
dentistry \\
2. Management of caries and periodontal risks \\
in general dental practice \\
3. Management of non-cavitated (initial) \\
occlusal caries lesions - non-invasive \\
approaches through remineralisation and \\
therapeutic sealants \\
4. Minimal intervention techniques of \\
preparation and adhesive restorations. \\
The contribution of the sono-abrasives \\
techniques \\
5. Ultra-conservative approach to the treatment \\
of erosive and abrasive lesions \\
6. Microscope and microsurgical techniques in \\
periodontics \\
7. Minimal intervention in cariology: the role of \\
glass-ionomer cements in the preservation of \\
tooth structures against caries \\
8. Biotherapies for the dental pulp \\
This paper is adapted from: Lallam C, Decup F. Gestion du risque \\
cario-parodontal en monipratique. Réalités Cliniques 2012 , \\
23: 175-189.
\end{tabular}

${ }^{1}$ Former Instructor, School of Dentistry, Paris 5 Descartes University, 65 rue Fessart, 92100 Boulogne, France; ${ }^{2}$ Associate Professor, Department of Conservative Dentistry, School of Dentistry, Paris 5 Descartes University, 78 Ave de la Grande Armée, 75012 Paris, France *Correspondence to: Franck Decup

Email: franck.decup@orange.fr

\section{Refereed Paper}

Accepted 15 November 2013

DOI: $10.1038 /$ sj.bdj.2014.143

${ }^{\circledR}$ British Dental Journal 2014; 216: 179-185
The pathological process results from the inseparable connections between all the factors of imbalance for a patient. Therefore, our clinical approach can only be one of comprehensive care, one that takes into account all the cross-cutting and longitudinal aspects of the disease (that is, all the tissues and all the stages).

Epidemiologic studies have revealed that dental caries and periodontal diseases are more likely to occur and develop in relation with some specific characteristics called risk factors. ${ }^{1-5}$ Some risk factors - including genetic factors - can't be changed. Still, knowing them helps understand and anticipate the occurrence of the disease and let the family know about it. Other factors however CAN be changed. This is the case of some behavioural characteristics such as eating too many sugary, decay-causing foods or poor plaque control leading to biofilm build up and caries and periodontal diseases. It is quite straightforward for practitioners and patients to change these. That is why as caregivers and public health providers we must act not only to treat the disease, but mostly to prevent it.

The continuous expansion of biological knowledge has made it possible to improve our understanding of caries and periodontal pathogenic developments, as well as patterns of tissue aggression. Furthermore, the various mechanisms of tissue repair have also become clearer, along with ways to induce or maximise them. ${ }^{6-9}$

These scientific advances are based on the notions of risk and of possible risk management. Thus, we only need to connect these theoretical elements to clinical practice so that they can be emphasised during diagnosis and treatment planning. This gives us increasingly effective tools against caries and periodontal diseases that are all the more difficult to manage as they are chronic diseases.

Screening of susceptible patients can be carried out before the onset of the diseases or in their very early stages. It is therefore possible to limit new pathogenic developments.

\section{What do we treat?}

Firstly, we treat a patient in an environment. His or her family, work and life habits need to be understood.

Secondly, we treat different types of tissues - teeth, periodontium, mucous membranes - that are totally interdependent and exposed to the same types of attacks.

A disease may not impact tissues similarly - nor have the same effects. Still, a comprehensive diagnostic and therapeutic approach should obviously identify all the factors and offer realistic, logical and consistent patient management. Today, cariology has adopted this clinical approach with the concept of minimal treatment that combines risk assessment and tissue preservation. ${ }^{10,11}$

In periodontology, this approach corresponds to the notion of global periodontal medicine ${ }^{12,13}$ and of periodontal risk assessment (PRA). ${ }^{14}$

In general dental practices it is possible 


\begin{tabular}{|c|c|c|c|c|}
\hline & Modifiable risk factors & $+l_{-}$ & Unmodifiable risk factors & +1 \\
\hline \multirow{4}{*}{$\begin{array}{l}\text { Systemic } \\
\text { factors }\end{array}$} & & & $\begin{array}{l}\text { Living conditions } \\
\text { Populations } \\
\text { Socio-economic environnement } \\
\text { Disabilities }\end{array}$ & \\
\hline & Controllable diseases (diabetes) & & Other systemic disorders (HIV) & \\
\hline & $\begin{array}{l}\text { Medicines: } \\
\text { Antisialic drugs (for example, } \\
\text { antidepressants, antiacne drugs, anti- } \\
\text { Parkinson drugs, analgesics, medications } \\
\text { to lower high blood pressure etc) } \\
\text { Immunosuppressants } \\
\text { Hormonal therapy } \\
\text { Chemotherapy }\end{array}$ & & Genetic predisposing factors & \\
\hline & $\begin{array}{l}\text { Physiological changes (for example, } \\
\text { puberty, pregnancy, menopause) }\end{array}$ & & Age & \\
\hline \multirow{5}{*}{$\begin{array}{l}\text { Behavioural } \\
\text { factors }\end{array}$} & Eating habits & & & \\
\hline & Poor oral hygiene & & & \\
\hline & Smoking & & & \\
\hline & $\begin{array}{l}\text { Addictive behaviours : } \\
\text { alcoholism, substance abuse }\end{array}$ & & & \\
\hline & Stress & & & \\
\hline
\end{tabular}

to manage both risks at the same time. This approach should be made easier and more systematic to meet patients' expectations regarding maintaining good oral health. The aim of this article is to suggest a global clinical approach. We will first explain a diagnostic method to define the patient's 'profile' and then we will offer individualised treatment options to limit the disease progression and associated risk factors.

\section{CARIES AND PERIODONTAL DIAGNOSIS - DEFINING THE PATIENT'S PROFILE}

All the surveys show that in addition to general information campaigns, every single dental practitioner plays a major role in enhancing prevention and early treatment and maintaining good oral health for everyone.

Practitioners' honed skills in anatomy, pathology and semiology are combined in the search for lesions. They probe and observe dental and periodontal tissues for better detection. Paradigms have changed along with patient examination. During the diagnostic phase, not only do practitioners examine the tissues, but they also try to find out what determines the various pathologies. It is important to identify whether the patient faces a high risk of developing caries and/or periodontal disease. ${ }^{15,16}$ Thus, it is necessary to identify each patient's specific imbalances, that is, local, systemic and behavioural risk factors (Table 1):

- Systemic risk factors refer to the individual's environment, for example, a given population, specific living conditions, disorders and medication, a certain age, genetic determinants and physiological alterations (Fig.1)

- Behavioural risk factors relate to the individual specifically and can all be modified in theory. This is the case with eating habits, oral hygiene, smoking, addictions or emotional stress. (Figs 2a and $2 \mathrm{~b}$ )

- Local risk factors - such as reduced salivary flow, plaque retention factors, periodontal biotype, bleeding, structural dental anomalies (Figs 3a and 3b) - are directly involved in the occurrence and progression of diseases.

No single factor is sufficient but putting these data together will generate the patient's profile.

The risk factors are to be collected based on the general examination at the time of the consultation (Tables 1 and 2). This takes into account information obtained during:

- The interview

- The clinical observation and additional examinations.

\section{Clinical interview and risk factors}

There is already a wide range of preventive strategies for high-risk groups, such as advertising campaigns, public health prevention measures, oral hygiene instruction programmes in specific establishments. Each practitioner is part of the chain and has to recognise these 'target populations'.

Early warning can be given if a patient is part of a target population. Epidemiological

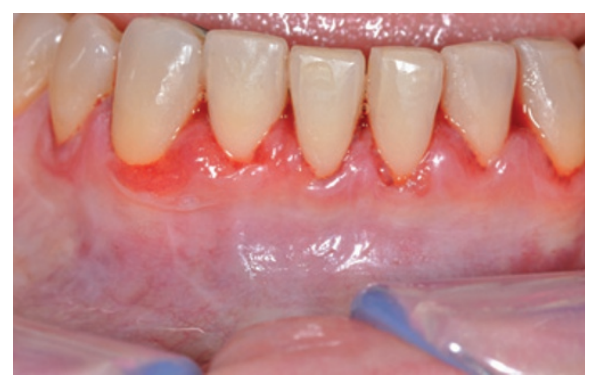

Fig. 1 This painful gingiva looks erosive and inflammatory but has no significant plaque build-up. During the preliminary interview, before the intrabuccal examination, the patient revealed he had AIDS which accounts for the appearance of the gums
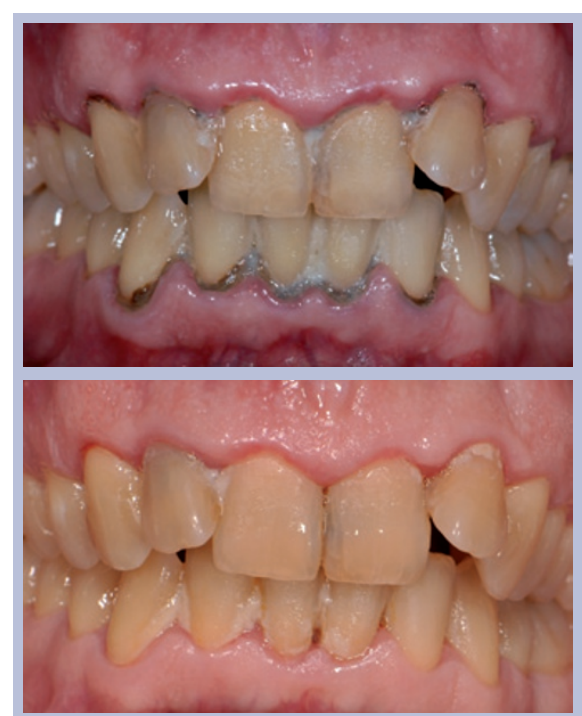

Fig. 2 Calculus is a local plaque retention factor. a) Gingival inflammation does not always correlate with the amount of calculus deposits. b) Patient's willingness to cooperate should be assessed quiclkly and after the teeth have been cleaned. The patient needs motivation advice and regular check-ups

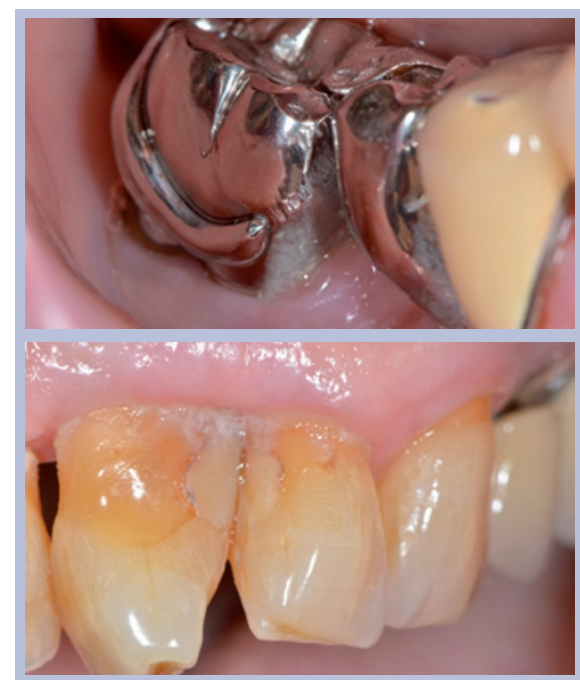

Fig. 3 Local factors increase the risk of possible unfavourable progression of caries or periodontal disease. That is why some anatomical elements, altered periodontium, or some iatrogenic restorations need to be detected and treated 


\begin{tabular}{|c|c|c|c|c|}
\hline & Modifiable risk factors & $+l_{-}$ & Unmodifiable risk factors & $+l_{-}$ \\
\hline \multirow{8}{*}{ Local factors } & $\begin{array}{l}\text { Quantity and quality of saliva } \\
\text { Biofilm }\end{array}$ & & & \\
\hline & $\begin{array}{l}\text { Active caries lesions } \\
\text { Conservative work done in the past } \\
\text { two years }\end{array}$ & & & \\
\hline & $\begin{array}{l}\text { Plaque retention factors: } \\
\text { tartar, iatrogenic elements, gingival } \\
\text { hyperplasia, malpositions }\end{array}$ & & & \\
\hline & $\begin{array}{l}\text { Periodontal biotype: } \\
\text { thin, medium or thick }\end{array}$ & & $\begin{array}{l}\text { Abnormalities of enamel } \\
\text { and dentin structure }\end{array}$ & \\
\hline & Age-related bone loss & & & \\
\hline & Number of missing teeth & & & \\
\hline & $\begin{array}{l}\text { Pocket depth greater than or equal } \\
\text { to } 5 \mathrm{~mm}\end{array}$ & & & \\
\hline & Bleeding on probing & & & \\
\hline
\end{tabular}

approaches have highlighted common sets of determinants in particular groups of people. The French Haute Autorité de Santé (High Health Authority) has published a cariology assessment that encourages practitioners to indicate if a patient belongs to one of the following risk groups (HAS 2010): ${ }^{17}$

- Dependent elderly people, whether in home care or in assisted living communities

- Disabled people, whether in home care or in assisted living communities

- People at high risks and/or with chronic conditions

- People from disadvantaged socioeconomic backgrounds in the case of children: catchment area (ZUS or 'sensitive urban zones') in the case of adults : socio-economic criteria such as people on CMUC (Supplementary Universal Health-Care Coverage, unemployed people, people from disrupted families, or on AME (State Medical Assistance)

- Migrant populations

- Prison population

- Pregnant women

- People with drug-induced hyposialia

- People who have had radiation therapy of the oral and maxillofacial area

- People involved in the food industry.

Age may well be a remarkable factor in carious lesions due to its associated characteristic behaviours, however, periodontal diseases should not be classified along an age-related gradient. Rapid progress is not specific to young patients and periodontal diseases have both quiet and active phases. ${ }^{18}$

Still, $80 \%$ of adults suffer from gingivitis and $50 \%$ present loss of attachment.
Frequency and severity increase with age and peak around 60 years old. Pregnant women and HIV-positive patients are target populations in periodontics.

Gingivitis occurs in 50\% of adolescents. Most of them are boys as they tend to have poorer oral hygiene. Periodontal diseases are thus more likely and require early screening and management (Fig. 4). ${ }^{19}$

Epidemiological studies have led to recording age in cariology. Key periods and ages have been noted. They relate both to the characteristics of the diseases that break out and the associated specific treatments to stop and prevent them: ${ }^{20-23}$

- 0-36 months: key ages six months old and two years old

- Three-six years: key age three years old

- 6-12 years: key ages six and nine years old

- 12-18 years: key ages 12 and 15 years old

- 18-25 years: key moment when young adults no longer live with parents

- 25-60 years

- >60: key retiring age.

Medical history taking provides information about patients' chronic diseases (diabetes). They may be well-controlled or poorlycontrolled. Additional information is also given about possible use of medications that induce physiological changes such as immune deficiency, hormone modifications or lower saliva flow. This medical interview is all the more useful as it is conducted systematically and supported by a written document.

Then, the clinical interview aims at emphasising risk behaviours - regular snacks, excessive sweets and soft drinks, inadequate living habits and poor oral hygiene practices. Identifying harmful habits and addictive

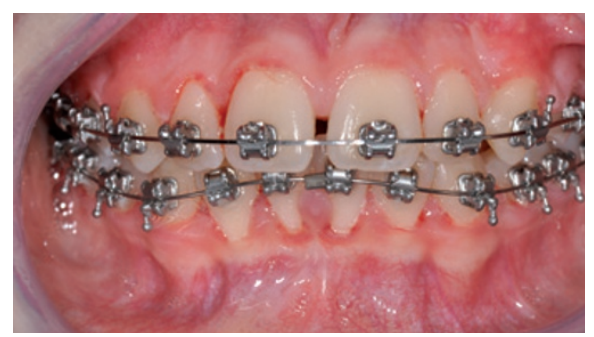

Fig. 4 The prevalence of gingivitis is higher during adolescence. This is especially true as plaque control is often irregular and is made more difficult in the case of orthodontic treatments

behaviours (smoking and drinking) is also essential in order to establish the profiles of our patients and provide them with appropriate treatments. Asking simple open questions such as "do you believe you have a balanced diet?' or 'do you think you have any health damaging habits?' can be useful.

A checklist may assist you in collecting information (Tables 1 and 2).

Though this epidemiologic approach helps make a diagnosis, it cannot replace the dentist's longitudinal assessment of each patient over the years. Thus, information about risk control can be obtained by analysing the behaviour and environment of a patient with good oral health stability. ${ }^{24}$

Comprehending the patient's environment is not the only thing to consider. It is also important to identify the local factors that are directly associated with the diseases and the tissues that are involved. This is done during the direct clinical examination and additional investigations.

\section{Clinical observation, addtional investigations and risk factors}

The standard examination of dental and periodontal tissues immediately reveals the presence or absence of bacterial biofilms, inflammation and lesions, along with their stage and activity (Table 2).

Lesions that are active or that have recently been treated such as periodontal pockets, bleeding, active caries or recent restorations are simple and easily objectifiable risk indicators in general practice. They are one of the most accurate predictors of the caries and periodontal disease progression risk in adults.

A high caries risk is identified when a patient has more than two active lesions together with lesions treated over the past two years. ${ }^{25}$ In 1996, Lang and Tonetti ${ }^{26}$ also established a list of not only subjects who are at periodontal risk, but also teeth and sites. This is based on the following criteria: the percentage of bleeding sites (more than $25 \%$ indicates a high risk), the percentage of five mm or deeper residual pockets (more than $8 \%$ indicates a high risk), the number 


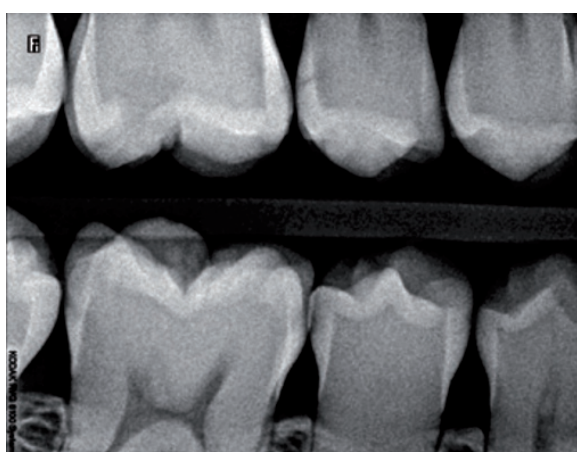

Fig. 5 Clinical and radiographic examinations have to be coupled to detect caries lesions that are often not visible to the naked eye

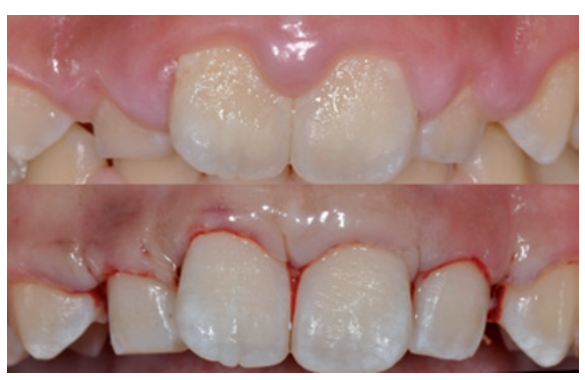

Fig. 6 Gingival hyperplasia is an obstacle to proper plaque control or bracket bonding and promotes new caries lesions. Surgery may be necessary to obtain a more favourable situation with more efficient plaque control and appropriate prescriptions

of missing teeth (more than eight indicates a high risk) and age-related bone loss.

When only a clinical examination is conducted, actual caries lesions are always underestimated. ${ }^{27}$ Moreover, a full periodontal assessment is hard to achieve. That is why the clinical examination should be coupled with bitewing and periapical X-rays (Fig. 5). Though therapeutic solutions including remineralising treatments have proved to be effective, ${ }^{28}$ the diagnosis for early enamel lesions, as well as their activity indicators, is too often overlooked. Thus, other diagnostic tools (optical aids, transillumination, laserinduced fluorescence etc) help refine assessment. They can also prevent diagnostic delays that are detrimental to prevention. ${ }^{29}$

Connecting these various observations is essential. Indeed, little plaque and numerous active lesions or, conversely, extensive biofilm and few lesions raises questions about the notions of risk and activity. Therefore, we need to have a clearer understanding of undetected general and/or local imbalance.

Clinical observation should go beyond the mere search for visible pathological signs. It must detect potential elements of local imbalance. These include plaque retention factors, factors preventing good hygiene such as tartar, iatrogenic restorations (Fig. 3), malpositions, orthodontic appliances or structural anomalies. ${ }^{30}$ Observation

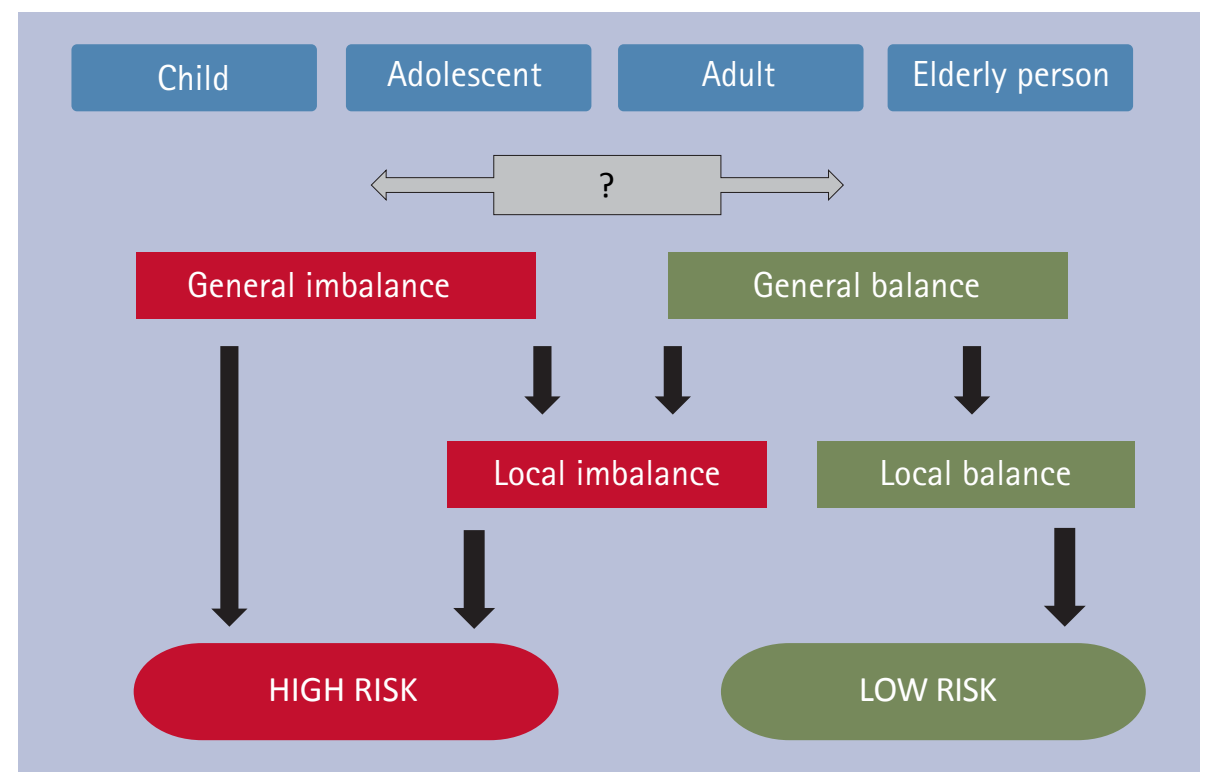

Fig. 7 Risk assessment according to general and local factors

should also reveal a thin periodontium or gingival hyperplasia (Fig. 6) that create a local environment prone to higher caries and periodontal risk. ${ }^{31}$

Thus, it is possible to combine all the elements about pathologies and the various risks and classify patients in focus groups. There are high caries and periodontal disease risk groups in the case of general and/or local imbalance - or low risk groups when there is little or no imbalance. Thus, these groups will be provided with adequate firstline treatments. This approach can only be successful if it is systematically taken with every patient (Fig. 7).

Today, the general dentist consultation needs to change into a synthetic caries and periodontal diagnosis. It should review the general and local risk factors. Thus, care needs as well as risk-related prevention needs are objectified. Moreover, patients can be given clear information to raise awareness and increase involvement in the treatment.

\section{CARIES AND PERIODONTAL DISEASE RISKS - WHAT CAN WE POSSIBLY DO? HOW TO ORGANISE RISK MANAGEMENT}

To be able to provide simpler and more repeatable advice and preventive procedures, it is necessary to make easier, more complete diagnoses and to determine the patient's profile.

Today, providing preventive care means trying to control risk factors, whether general or local. This is done during the treatment's so-called prophylactic phase. This phase is also called 'early therapeutic phase' as it consists in restoring the balance, treating the disease and removing the lesions before the restorative or the consolidation phases. ${ }^{32,33}$

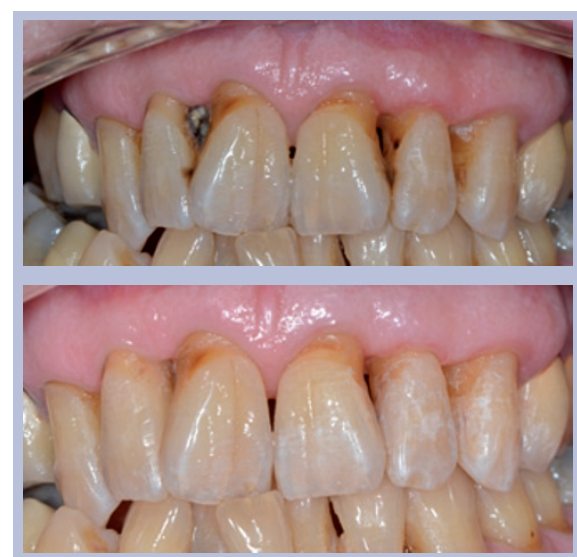

Fig. 8 The disease persists because of local risk factors - cavitated lesions or calculus. When these are removed, biofilm control and periodontal healing are greatly improved

We have seen that this therapeutic approach could not work with such risk factors as systemic diseases, genetic predispositions, anatomic abnormalities. Those are the nonmodifiable risk factors - they cannot be changed and prophylactic care should try to compensate for these weaknesses.

Many more risk factors, the modifiable ones, can be removed or monitored:

- We can impact behavioural

characteristics - eating and hygiene habits, smoking, drinking, drug addictions etc - by giving information, explanations (to promote better awareness) and advice (to offer solutions)

- It is also possible to change the local factors. Medical steps are taken first - improving biofilm removal and control and using remineralising and antiseptic molecules. Then, more invasive, even surgical steps can be the socioeconomic environment or some 
taken as well - cleaning, repairing or replacing iatrogenic restorations, reducing inflammation or treating cavitated carious lesions (Figs 8a and b).

\section{Behaviour management}

All high-risk patients must be given the opportunity to reassess their specific habits, regardless of whether their risk factors are local or general.

Changing one's behaviour is notoriously difficult. Motivation cannot be prescribed, it can only be stimulated. It is not reason that determines motivation, but the pleasure-displeasure ratio. Core behavioural modifications are based on the very own resources of the patient. That is why the strategy we are proposing includes the following: ${ }^{34}$

1. Understand patients' views on their oral health

2. Identify their limitations

3. Bolster patients' self-esteem by paying special attention to them

4. Set gratifying achievable objectives in the long term.

Obviously there is much to be learned from simple, guilt-free explanations about the pathological process and its bacterial causes. Clear and simple sentences should be used, for example: 'everybody has a mouth full of bacteria but disrupting a person's individual balance may trigger caries and/ or periodontal diseases. That is why our primary focus of action should be to keep the right balance.' We can thus proceed with the notion of disruption caused by dietary habits - too much sugar and acid - the effects of smoking, drinking, doing drugs or not taking good care of one's oral health. However, too much information is useless. What matters is to put forward the patient's best interest to make a full recovery. Therefore, it is important to explain the connection between some behaviours and the disease - put the pain on hold, achieve better comfort and aesthetics.

As far as the harmful habits are concerned, it is useful to start giving periodic advice as early as possible, while keeping in mind the patient's way of life. It is important to talk about food, alcohol, tobacco or substance abuse in a tactful yet uncompromising way. The condition must be addressed with utmost objectivity. The objective is to build an enduring therapeutic alliance. ${ }^{34}$ Each of us is free to proceed using individual skills or refer the patient.

Two therapeutic aids have been readily available to us - the eating survey ${ }^{35}$ and smoking cessation support with explanatory brochures available online at tabac-infoservice.fr. ${ }^{36}$ Furthermore, their growing use is recommended with regard to public health.

Dietary management requires looking at any abnormal sugar or acid intake and to remind patients who may not know the list of cariogenic foods, such as ketchup, potato chips as well as some drugs. In addition, patients should be warned against harmful repeated food intake, for example it is not so much the more sugar you take, but the more often you take sugar that will harm your teeth and gums'.

Finally, general modifiable factors have to be monitored as well by asking the patient to effectively control diabetes, hormonal disruptions or vitamin deficiencies. Dental surgeons are rightful members of the medical team and must monitor and pass on information about those diseases that directly impact both the caries and periodontal risk and overall health.

\section{Management of local factors}

Every patient should benefit from appropriate local prophylactic treatments. Today, many options are available though some may be difficult to handle and prescribe accurately.

a) Firstly, teaching plaque control.

Showing how to use appropriate tools to remove plaque mechanically with:

- A manual toothbrush

- A rotating or oscillating-rotating toothbrush

- Interdental cleaners such as brushes, floss, soft toothpicks.

- A water jet may be used along with brushing in case of complex prosthetic restorations or physical limitations.

It is necessary to disclose plaque beforehand by picking it or dying it with a disclosing solution. The advantages of technique and tool options have been discussed in several Cochrane reviews. ${ }^{37,38}$ The latest study, which was published in 2009, shows that electric brushing is more effective than manual brushing thanks to new brush models that are gentle on even the most fragile periodontium. Again, dentists should give individual advice as how to use them.

b) In addition to the mechanical removal of the biofilm, several active ingredients are of interest when controlling attacks and optimising defences. Thus, it is recommended to use toothpastes, mouthwashes or varnishes that contain antiseptics (chlorhexidine) and remineralising molecules such as fluoride and calcium phosphate. ${ }^{39-42}$

c) First-line clinical procedures also need to be carried out to clean bacterial sites and treat inflammation. It is necessary to eliminate the risk factors that are directly associated with the disease by cleaning the

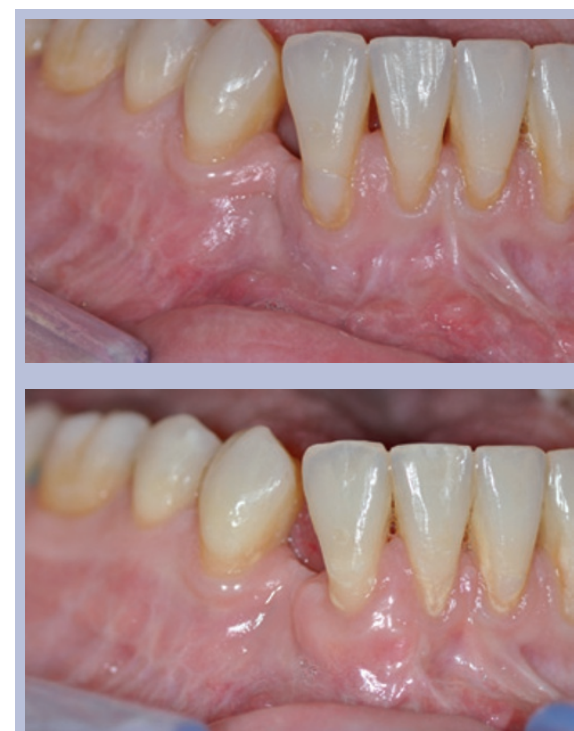

Fig. 9 A periodontium with a thin biofilm may be a risk factor for evolution of recession. It can be modified by surgery. This patient had a flap displacement coupled with deep conjunctive technique. This procedure enabled to change the mucogingival area by thickening the periodontium. The planned orthodontic treatment can now start optimally

teeth, adjusting ill-fitting restorations, filling cavitating caries lesions or eliminating possible sites for food debris to accumulate. Risk management can go beyond this first phase and change tissue anatomy. Thus, orthodontic treatment or the surgical modification of an unfavourable periodontal biotype may be necessary (Figs 9a and b).

\section{CLINICAL SITUATIONS - SPECIFIC GROUP PRESCRIPTIONS}

Prescribing is an essential approach in first-line disease management during the prophylactic treatment phase. The general dentist's recommendations to tackle modifiable risk factors should be supported by a written prescription. Clear and specific explanations can thus be provided as to which tools and products best correspond to the risk and the disease. On the one hand, patients can use prescriptions as a written reminder of the advice they have been given during the clinical interview. They can refer to them from their homes. On the other hand, practitioners may use modifiable prescription templates to target preestablished focus groups and individual patients within these groups. Prescription details can be found online in the supplementary information associated with this article.

\section{CLINICAL CASES}

\section{Clinical case \# 1 (Fig. 10)}

Healthy 13-year-old adolescent. Parents are shopkeepers. Lives in residential area 
in Lyon. Referred by orthodontist during treatment with fixed appliances.

No caries lesions revealed by the clinical examination - plaque and generalised gingivitis can be noted.

Eating between meals is not uncommon. Familial predisposition exists - mother suffers from periodontitis.

\section{Identification}

There are both general (familial) nonmodifiable risk factors and many local risk factors. The familial predisposition should be regarded as a warning sign. Behavioural risk factors - frequent snacking - should be changed and the local imbalance due to orthodontic crowding should be corrected.

This is a high caries and periodontal risk patient.

\section{Recommendations}

Simple explanations to limit the progress of caries and periodontal disease are provided as early as the first visit - they include brushing and eating advice and a motivation boost. Periodic bi-annual check-ups are recommended.

\section{Prescription}

'High-risk adolescent/disrupted oral balance' template.

\section{Clinical case \#2 (Fig. 11)}

Thirty-two-year-old single man with good overall health with a smoking habit. Lives in the city and often goes out in the evening. The clinical examination reveals several active caries lesions, many existing restorations, calculus deposits and gingival inflammation. Patient presents with chronic generalised mild periodontitis.

\section{Identification}

This patient has general risk factors - living habits, smoking - and many local factors - caries lesions, plaque, calculus, one iatrogenic restoration and missing teeth. He is considered 'at risk'. Oral imbalance is both local and general with some modifiable factors.

\section{Recommendations}

Simple explanations about caries and periodontal diseases are given soon after emergency treatment.

Given the patient's wish to change, feasibility is assessed and new balanced objectives are agreed on. Brushing and healthy eating advice is provided and smoking cessation is encouraged.

\section{Prescription}

'High-risk adult' template.

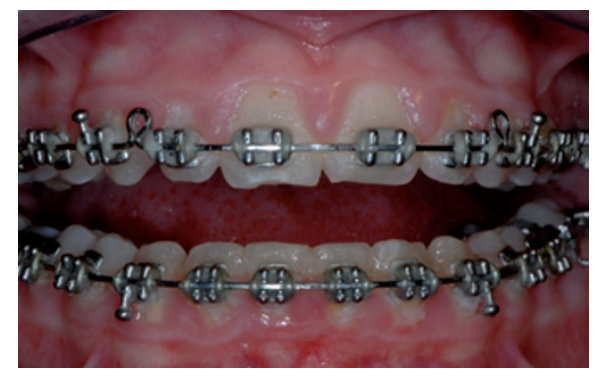

Fig. 10 Healthy 13-year-old adolescent with plaque and generalised gingivitis
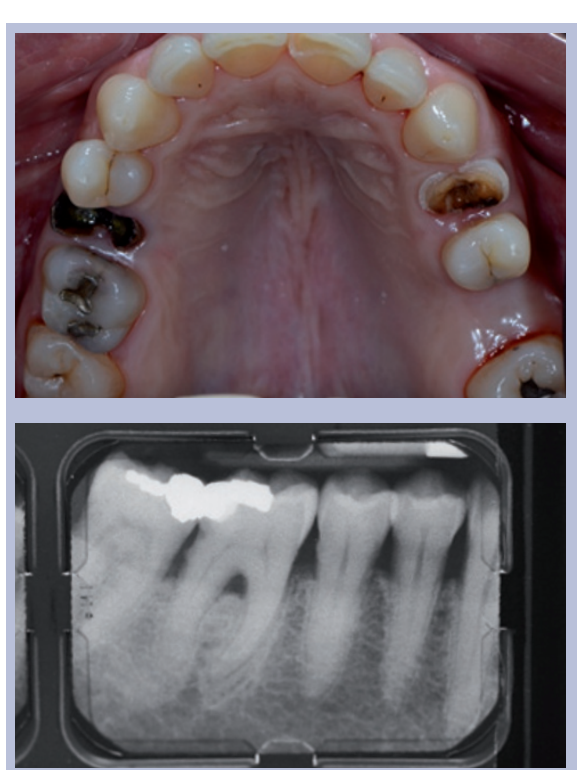

Fig. 11 Thirty-two-year-old male smoker with several active caries lesions, many existing restorations, calculus deposits and gingival inflammation. Patient presents with chronic generalised mild periodontitis

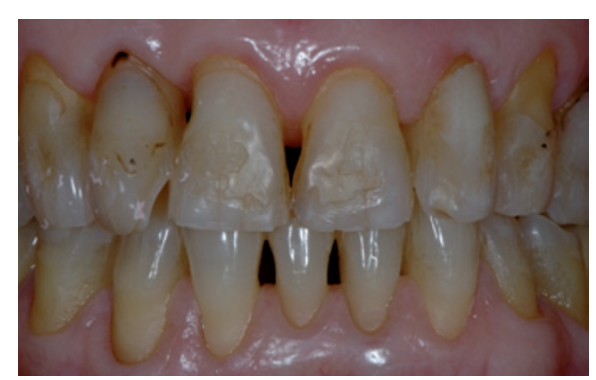

Fig. 12 Seventy-nine-year-old retired woman with controlled high-blood pressure, with little or no visible inflammation of the gums

\section{Clinical case \# 3 (Fig. 12)}

Married 79-year-old retired woman with controlled high-blood pressure.

Came in for check-up after three-year interruption. The clinical examination reveals that plaque is under control, fillings are well-adapted, there are no new caries and little or no visible gingival inflammation. Eats sensibly.

\section{Identification}

Attention should be paid to the patient's age group as she belongs to a target population.
After interviewing and examining the patient, it is determined that there are no risk factors present.

\section{Recommendations}

Explanations about physiological tissue changes can be given - possible root exposure, open embrasure etc. Annual check-ups are recommended.

\section{Prescription}

'Low-risk senior citizen' template.

\section{CONCLUSION}

Thanks to scientific elements that support the management of caries and periodontal disease risk, we can now better prevent and screen the more susceptible patients before or at the very onset of the diseases.

Though this approach is not covered by insurance in France, it is absolutely necessary to deliver the best possible oral care strategy in the long term. Practitioners are empowered and patients are more committed to their treatments. Developing a clear vision of this organised approach makes it easier for us to start implementing it routinely. It has been noticed that highrisk patients tend to suffer from repeated bouts of periodontal disease and experience significantly higher dental loss rate. That is why it is essential to screen these patients as early as the initial stages of the treatment. Limiting the risk factors thanks to prevention, treating incipient lesions and, most importantly, planning the support therapy will achieve stable enduring results.

In a general dental practice, the challenge is to use this approach systematically with every patient, while taking account of the specific needs of each and every one of them and provide individualised care.

The authors would like to thank Claudie DamourTerrasson, publishing director of the Groupe Information Dentaire, Paris, France, for the authorisation of translation and publication of the series in the BDJ and Pascale Eisenberger for her translation assistance.

Sheiham A, Watt $R$ G. The common risk factor approach: a rational basis for promoting oral health. Community Dent Oral Epidemiol 2000; 28: 399-406.

2. Featherstone J D, Adair S M, Anderson M H et al. Caries management by risk assessment: consensus statement, April 2002. J Calif Dent Assoc 2003; 31: 257-269.

3. Nussbaum G, Shapira L. How neutrophils research improved our understanding of periodontal pathogenesis? J Clin Periodonto/ 2011; 38: 49-59.

4. Zhao L, Lin H C, Lo E C, Wong M C. Clinical and socio-demographic factors influencing the oral health-related quality of life of chineese elders. Community Dent Health 2011; 28: 206-210.

5. Lee J, Taneja V, vassallo R. Cigarette smoking and inflammation cellular and molecular mechanisms. J Dent Res 2011; 91: 142-149.

6. Clark R A F. Wound repair. Overview and general considerations. In Clark R A F (ed) The molecular and cellular biology of wound repair. 2nd ed. pp 1-50. 
New York: Plenum press, 1996.

7. Hennequin M. Dynamique du processus carieux initial. Réalités Cliniques 1999: 10: 483-501.

8. Featherstone J D. The caries balance: the basis for caries management by risk assessment. Oral Health Prev Dent 2004; 2: 259-264.

9. Lallam-Laroye $C$, Baroukh B, Doucet $P$, Barritault D, Saffar J L, Colombier M L. Regeneting agents matrix therapy regenerates a functionnal root attachment in hamsters with periodontitis. Tissue Eng Part A 2011; 17: 2359-2369.

10. Young D A, Featherstone J D, Roth J R et al. Caries management by risk assessment: implementation guidelines. J Calif Dent Assoc 2007 ; 35: 799-805.

11. Doméjean S, Maret D, Van Der Sluis L, Decerle N, Featherstone J D B. Evaluation CAMBRA du risque carieux. Clinic 2012; 33: 187-192.

12. Pihlstrom B L, Michalowicz B S, Johnso N W. Periodontal diseases. Lancet 2005; 366: 1809-1820.

13. Bourgeois D, Bouchard P, Mattout C. Epidemiolgy of periodontal status in dentate adults in France, 2002-2003. J Periodont Res 2007; 42: 219-227.

14. Lang N P, Tonetti M S. Periodontal risk assessment (PRA) for patients in supportive periodontal therapy (SPT). Oral Health Prev Dent 2003; 1: 7-16.

15. Feartherstone JDB. The caries balance : contributing factors and early détection. J Cal Dent Assoc 2003; 31: 129-133.

16. Fontana M, Zero D. Assessing patients'caries risk. J Am Dent Assoc 2006; 137: 1231-1240.

17. Évaluation des stratégies de la prévention de la carie dentaire. HAS-santéfr 2010.

18. Hugoson A, Sjödin B, Norderyd O. Trends over 30 years, 1973-2003 in the prévalence and severity of periodontal disease. J Clin Periodontol 2008; 35: 405-414.

19. Parodontopathies: diagnostic et traitements. ANAES 2002. Online article available at http://www. has-sante.fr/portail/upload/docs/application/pdf/ Parodontopathies_rap.pdf (accessed December 2013).
20. Griffin S O, Griffin P M, Swann J L, Zlobin N. Estimating rates of new root caries in older adults. J Dent Res 2004; 83: 634-638.

21. Bourgeois D M, Roland E, Desfontaine J. Caries prevalence 1987-1998 in 12-year-olds in France. Int Dent J 2004; 54: 193-200.

22. Petersen $P$ E, Yamamoto T. Improving the oral health of older people: the approach of the Who global health programme. Community Dent Oral Epidemiol 2005; 33: 81-92.

23. Ramos-Gomez F J, Crystal Y O, Doméjean S, Featherstone J D B. Prévention et prise en charge de la maladie carieuse basées sur l'évaluation du risque chez les jeunes enfants. Réalités Cliniques 2011; 22: 221-232.

24. Brocklehurst P R, Ashley J R, Tickle M. Patient assessment in general dental practice-risk assessment or clinical monitoring? Br Dent J 2011; 210: $351-354$

25. Fontana M, Gonzalez-Cabezas C. Évaluation du risque carieux chez l'adulte. Real Clin 2011; 22: 213-219.

26. Lang N P, Tonetti M S. Periodontal diagnosis in treated periodontitis. Why, when and how to use clinical parameters. J Clin Peridontol 1996; 23 : 240-250.

27. Pitt NB. Are we ready to move from operative to non opérative/préventive treatment of dental caries in clinical pratice? Caries Res 2004; 38: 294-304.

28. Miller C, Ten Cate J M, Lasfargues J J. La reminéralisation des lésions carieuses : le rôle essentiel des fluorures. Réalités Cliniques 2004; 15: 249-260.

29. Lasfargues J J, Colon P. Maladie carieuse. In Odontologie conservatrice et restauratrice. Tome 1: une approche médicale globale. Paris Ed CDP 2010

30. Opsahl Vital S, Haignere-Rubinstein C, Lasfargues $\mathrm{J} J$, Chaussain C. Caries risk and orthodontic treatment. Int Orthod 2010; 8: 28-45.

31. Eghbali A, De Rouck T, De Bruyn H, Cosyn J. The gingival biotype assessed by experienced and inexperienced clinicians. J Clin Periodontol 2009; 36:
958-963.

32. Feartherstone J D, Doméjean S. Le concept d'intervention minimale en cariologie. Réalités Cliniques 2011; 22: 207-212

33. Petersilka G J, Ehmke B, Flemmig T F. Antimicrobial effects of mechanical debridement. Periodontol 2000; 2002: 28: 56-71.

34. Grimaldi A. L'observance : le défi de la maladie chronique. Revue de médecine interne 2009; 30: 1-2.

35. Miller $C$, Lasfargues JJ.Diététique et prévention dentaire. Cahier rédactionnel. Inf Dent 1999.

36. Filoche S K, Cornford E, Gaudie W, Wong M, Heasman P, Thomson W M. Smoking, chronic periodontitis and smoking cessation support: reviewing the role of dental professionals. NZDent J 2010; 106: 74-77.

37. Robinson P G, Deacon S A, Deery C et al. Manual versus powered toothbrushing for oral health. Cochrane Database Syst Rev 2005; CD002281.

38. Slot D E, Dörfer $C E$, Van der Weijden G A. The efficacy of interdental brushes on plaque and parameters of periodontal inflammation: a systematic review. Int J Dent Hyg 2008; 6: 253-264.

39. Marinho V C, Higgins J P, Logan S, Sheiham A. Topical fluoride (toothpastes, mouthrinses, gels or varnishes) for preventing dental caries in children and adolescents. Cochrane Database Syst Rev 2003; CD002782.

40. Benson P E, Parkin N, Millett D T, Dyer F, Vine S, Shah A. Fluorides for the prevention of white spots on teeth during fixed brace treatment. Cochrane Database Syst Rev 2004; CD003809.

41. Bonner B C, Clarkson J E, Dobbyn L, Khanna S. Slowrelease fluoride devices for the control of dental decay. Cochrane Database Syst Rev 2006; CD005101.

42. Walsh T, Worthington H V, Glenny A M, Appelbe P, Marinho V C, Shi X. Fluoride toothpastes of different concentrations for preventing dental caries in children and adolescents. Cochrane Database Syst Rev 2010; CD007868. 